Published by Al-Nahrain College of Medicine P-ISSN 1681-6579

E-ISSN 2224-4719

Email: iraqijms@colmed-alnahrain.edu.iq

http://www.colmed-alnahrain.edu.iq

http://www.iraqijms.net

Iraqi JMS 2018; Vol. 16(2)

\title{
Clinical Utility of Urinary Antigen Test and Molecular Method for Detection of Legionella Pneumophila
}

\author{
Shaymaa A. Gauad ${ }^{1} H D$, MSc, Thanaa R. Abdulrahman² PhD, Amar k. Muhamad ${ }^{3}$ FICMS, \\ Asmaa A. Jawad ${ }^{4} B S C$, Jabbar S. Hassan ${ }^{2} P h D$
}

\begin{abstract}
${ }^{1} \mathrm{Al}$-Shahid Mohammad Baqir Al Hakeem Hospital, Baghdad, Iraq, ${ }^{2}$ Dept. of Microbiology, College of Medicine, AlNahrain University, Baghdad, Iraq, ${ }^{3} \mathrm{Al}-$ Imamein Al-Kadhimein Medical City, Baghdad, Iraq, ${ }^{4}$ Forensic DNA Research and Training Center, Al-Nahrain University, Baghdad, Iraq
\end{abstract}

\begin{abstract}
Background Legionella pneumophila (L. pneumophila) is gram-negative bacterium, which causes Legionnaires' disease as well as Pontiac fever.

Objective To determine the frequency of Legionella pneumophila in pneumonic patients, to determine the clinical utility of diagnosing Legionella pneumonia by urinary antigen testing (LPUAT) in terms of sensitivity and specificity, to compares the results obtained from patients by urinary antigen test with q Real Time PCR (RT PCR) using serum samples and to determine the frequency of serogroup 1 and other serogroups of $L$. pneumophila.

Methods A total of 100 pneumonic patients (community acquired pneumonia) were enrolled in this study during a period between October 2016 to April 2017; 92 samples were collected from patients attended and admitted to Al-Imamein Al-Kadhimein Medical City and 8 samples from those in the (Center of Kidney Diseases and Transplantation) in the Medical City of Baghdad. All patients were under therapy with antibiotics. Serum and urine specimens were obtained from all patients; urine samples were processed for urinary antigen test (rapid test). Serum samples were collected and submitted to DNA extraction for detection of L. pneumophila mip gene by q RT PCR assay.

Results The percentage of L. pneumophila in two hospitals in Bagdad was 30\%. Of these $26 \%$ was serogroup 1 detected by urinary antigen testing (UAT). In the other hand, $23 \%$ of samples were positive by q RT PCR based mip gene, of these $19 \%$ were serogroup 1 and $4 \%$ were another serogroup. The sensitivity of UAT is high (P value $<0.001$ ), which means statistically highly significance than q RT PCR.

Conclusion LPUAT is a rapid tool for early diagnosis of Legionella infection, which highlights the need of using this test in hospitals and health institutions and there is a high prevalence of $L$. pneumophila in Iraq that refer to the necessity of considering this microorganism point of view in future studies for detection and treatment in pneumonic patients.
\end{abstract}

Keywords L. pneumophila, mip gene, quantitative real time PCR, urinary antigen.

Citation Gauad SA, Abdulrahman TR, Muhamad AK, Jawad AA, Hassan JS. Clinical utility of urinary antigen test and molecular method for detection of Legionella pneumophila. Iraqi JMS. 2018; 16(2): 207-215. doi: 10.22578/IJMS.16.2.13

List of abbreviations: DFA = direct fluorescent antibody, $I \mathrm{HC}=$ immunohistochemistry, LD = Legionnaires' disease, LPUAT = Legionella pneumonia by urinary antigen testing, mip = Macrophage infectivity pointier gene, q RT PCR = quantitative real time polymerase chain reaction, sg1 = serogroup one, TALD = Travel-associated legionnaire's disease, UAT = urinary antigen test

\section{Introduction}

egionnaires' disease (LD) is an acute
pneumonia caused by Legionella spp.
Legionella is Gram-negative bacteria ubiquitous in both man-made and natural aquatic reservoirs, it is reported that up to $90 \%$ of cases of LD is caused by Legionella pneumophila ${ }^{(1)}$. Of the 50 species and 72 serogroups belonging to the genus Legionella, L. pneumophila serogroup one (sg1) is responsible for at least $80 \%$ of human infections ${ }^{(2)}$. 
Legionellosis has two distinct clinical presentations: Pontiac fever, a self-limited, febrile, flulike illness; and LD, which is an atypical pneumonia (3). Peoples living in warm climate area are considered as at-risk population due to the direct and prolonged exposure to air-conditioning and air-circulating systems ${ }^{(4)}$.

Risk factors for legionellosis include whirlpool spa exposure, recent overnight travel or plumbing repairs (two weeks prior to onset of symptoms), immunosuppression, alcoholism, diabetes, malignancy, hepatic or renal failure, chronic obstructive lung disease, smoking history, and patient age $>50$ years ${ }^{(5)}$.

Conventional methods for diagnosis of LD consist of culture, antigen detection in urine (UAT), serological testing, and direct fluorescent antibody (DFA) staining or immunohistochemistry (IHC) ${ }^{(6)}$.

L. pneumophila urinary antigen testing (LPUAT) is a rapid tool for early diagnosis of Legionella infection in urine sample ${ }^{(6)}$. Real time PCR (RT $P C R)$ a rapid and sensitive method for the detection of LD based on the use of macrophage infectivity potentiator gene (mip gene), which encodes a $24-k D a$ protein virulence factor ${ }^{(7)}$.

mip gene facilitates the entry of legionellae into amoebae and macrophages. It has sufficient sequence variability between the Legionella species to also afford the specific detection of L. pneumophila by PCR ${ }^{(7)}$.

This study aimed to determine the frequency of $L$. pneumophila in pneumonic patients in addition to determine the clinical utility of diagnosing LPUAT in terms of sensitivity and specificity then compares the results of UAT with q real time PCR using serum samples. In Iran the seroprevalence rate of $L$. pneumophila in admitted patients with pneumonia was $17.3 \%$ while in Austria and Trinidad were $0.65 \%$ and $31.7 \%$ respectively ${ }^{(8)}$.

\section{Methods}

Study setting and design
A total of 100 patients with (community acquired pneumonia) were confirmed by chest radiography (CXR) and enrolled in this study during a period between October 2016 to April 2017, 92 serum and urine specimens were obtained from patients admitted to admitted to Al-Imamein Al Kadhimein Medical city and 8 samples from the (Center of Kidney Diseases and Transplantation) in the Medical City of Baghdad.

Clinical inclusion criteria: Patients older than 20 years, Respiratory Care Unite patients and medical word, diabetic, smoking, chronic lung disease, renal transplant, immunocompromised and cancer patients and those receiving corticosteroid treatment.

Exclusion criteria: patients with atypical pneumonia less than 20 years old.

Urine samples were processed for UAT (rapid test) and DNA was extracted from serum to detect the presence of mip gene of $L$. pneumophila by q RT PCR assay.

\section{Urinary antigen detection test}

The presence of $L$. pneumophila sg1 antigens in urine specimens was determined according to manufacture instructions using qualitative immunochromatographic (CerTest; Spain) assay.

\section{DNA extraction}

Bacterial DNA was extracted from serum samples using DNA-Sorb-B extraction kit components (Sacace ${ }^{\mathrm{TM}} /$ Italy).

\section{Real Time PCR Protocol}

According to the company and factory instructions, controls were prepared for each quantitative test as follow: $10 \mu$ l of DNA-buffer was added to the tube labeled amplification negative control; $10 \mu \mathrm{l}$ of QS1, QS2 and QS3 were added to the tubes labeled QS1, QS2, QS3 respectively. A required quantity of PCR-mix-1 reaction tubes were prepared for samples and controls, $7 \mu$ of PCR-mix-2 was added on the wax surface, $10 \mu \mathrm{l}$ of extracted DNA then added to appropriate tube. RT PCR was performed on Rotor-Gene Q, (Qiagen Germany) and DNA was amplified according in 
the thermal cycler for thermal profile showed in table 1.

The analysis results are considered valid, only if the control samples of the quantitative test results comply the following, table 2 .

Table 1. Legionella pneumophila q RT PCR amplification profile

\begin{tabular}{|c|c|c|c|c|c|c|}
\hline \multirow[b]{2}{*}{ Step } & \multicolumn{3}{|c|}{ Rotor-type Instruments $^{1}$} & \multicolumn{3}{|c|}{ Plate type Instruments ${ }^{2}$} \\
\hline & $\begin{array}{c}\text { Temperature } \\
{ }^{\circ} \mathrm{C}\end{array}$ & Time & Repeats & $\begin{array}{c}\text { Temperature } \\
{ }^{\circ} \mathrm{C}\end{array}$ & Time & Repeats \\
\hline 1 & 95 & $15 \mathrm{~min}$ & 1 & 95 & $15 \mathrm{~min}$ & 1 \\
\hline \multirow{3}{*}{2} & 95 & $5 \mathrm{~s}$ & & 95 & $5 \mathrm{~s}$ & \multirow{3}{*}{5} \\
\hline & 60 & $20 \mathrm{~s}$ & 5 & 60 & $20 \mathrm{~s}$ & \\
\hline & 72 & $15 \mathrm{~s}$ & & 72 & $15 \mathrm{~s}$ & \\
\hline \multirow{3}{*}{3} & 95 & $5 \mathrm{~s}$ & \multirow{3}{*}{40} & 95 & $5 \mathrm{~s}$ & \multirow{3}{*}{40} \\
\hline & 56 & $\begin{array}{c}20 \mathrm{~s} \\
\text { fluorescent } \\
\text { signal } \\
\text { detection }\end{array}$ & & 56 & $\begin{array}{c}30 \mathrm{~s} \\
\text { fluorescent } \\
\text { signal } \\
\text { detection }\end{array}$ & \\
\hline & 72 & $15 \mathrm{~s}$ & & 72 & $15 \mathrm{~s}$ & \\
\hline
\end{tabular}

Table 2. Legionella pneumophila q RT PCR amplification profile

\begin{tabular}{ccccc}
\hline Control & Stage for control & $\begin{array}{c}\text { Ct channel } \\
\text { FAM/Green }\end{array}$ & $\begin{array}{c}\text { Ct channel } \\
\text { JOE/Yellow }\end{array}$ & Interpretation \\
\hline C- & DNA isolation & Pos & Neg & OK \\
C+ & DNA isolation & Pos & Pos & OK \\
DNA buffer & Amplification & Neg & Neg & OK \\
QS1 & Amplification & Pos & Pos & OK \\
QS2 & Amplification & Pos & Pos & OK \\
QS3 & Amplification & Pos & Pos & OK \\
\hline
\end{tabular}

\section{Legionella pneumophila DNA quantification}

The concentration of $L$. pneumophila DNA in control and samples were calculated according to the following equation:

C L.pn. DNA (cop/L) = K L.pn. DNA/KIC $\times$ CIC $\times 2$

- C L.pn. DNA (cop/L) - quantity of $L$. pneumophila DNA copies in $1 \mathrm{~L}$ of sample

- K L.pn. DNA (cop/ml) - calculated quantity of $L$. pneumophila DNA copies in $1 \mathrm{ml}$ of sample; KIC (cop/ml) - calculated quantity of IC DNA copies in $1 \mathrm{ml}$ of sample

- $\mathrm{CIC}(\mathrm{cop} / \mathrm{ml})$ - quantity of IC DNA copies in 1 $\mathrm{ml}$ of IC according to Data Card

- 2 - adjustment for sample filtration
1. The calibration curve correlation coefficient R2 must be more than 0.97

2. The Efficiency value must be in range: $0.85-$ 1.15

\section{Questionnaire}

All participants were surveyed using a standard questionnaire, whereby the following information was collected: (age, gender, work); environmental risk factors (residence, travel and bad water supplies); epidemiological risk factors (smoking, diabetes, chronic obstructive pulmonary disease (COPD), asthma, hepatic or renal failure, kidney transplant, malignancy) 
and serum sodium electrolyte as laboratory finding.

\section{Statistical Analysis}

The statistical analysis of this prospective study performed with the statistical package for social sciences (SPSS) 21.0 Software and Microsoft Excel 2013. Numerical data were described as mean, standard deviation and median with $95 \%$ confidence intervals. Chisquare test or Fisher exact test was used to describe the association between variables.

\section{Results}

In this study, the percentage of L. pneumophila in two hospitals in Baghdad was $30(30 \%)$ by both UAT and q RT PCR. Of these, 26 (26\%) was sg1 detected by UAT. In the other hand, 23 (23\%) were positive by q RT- PCR based mip gene, 19 (82.6) out of 23 patients were positive for mip gene-based PCR and UAT, which considered to be true positive for sg1 while only $4 \%$ were another serogroup. The sensitivity $(95 \% \mathrm{Cl})$ of UAT is $82.61 \%$ and Specificity $(95 \% \mathrm{Cl}) 90.91 \%$ with (P value < 0.001), which means statistically highly significance than q RT PCR, (table 3).

The mean of mip gene was 8.76 copies $/ \mathrm{ml}$ for pneumonic patient with LD. Minimum copy was 0 and maximum 68.35 copies $/ \mathrm{ml}$. figure (1).

Table 3. Comparisons of $q$ RT PCR in serum samples versus UAT in urine

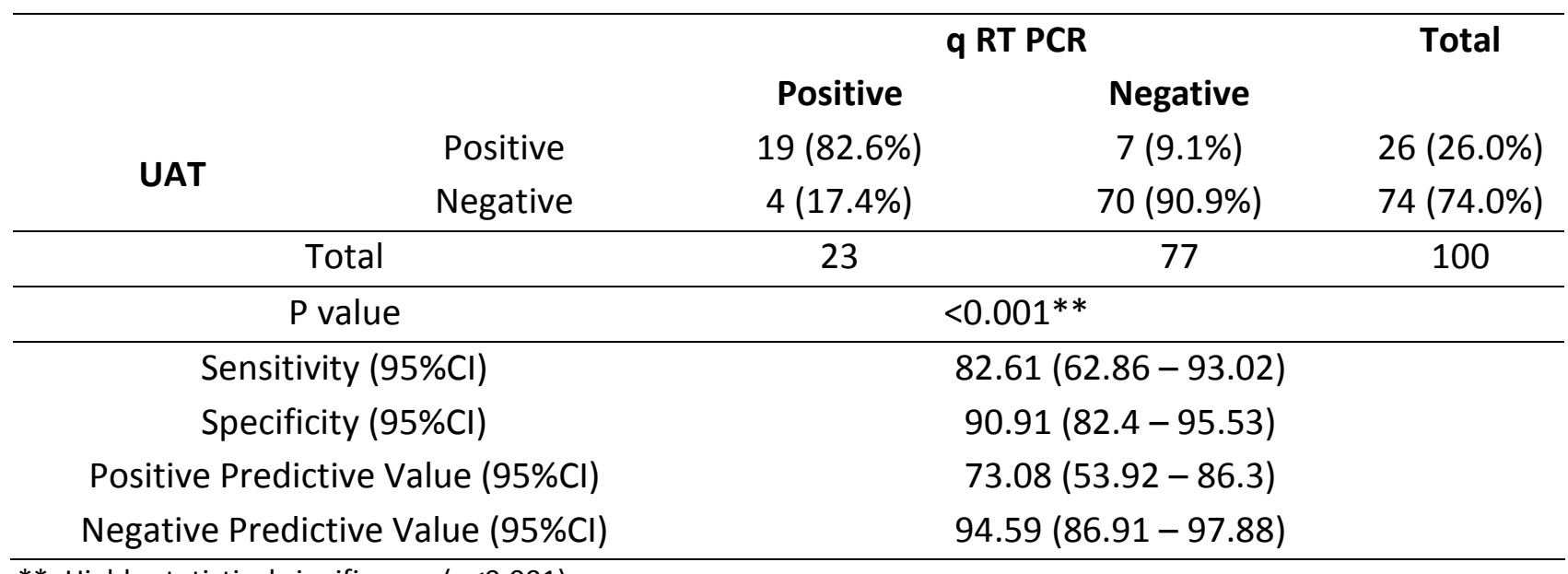

**: Highly statistical significance $(p \leq 0.001)$

\section{LD according to the age group.}

In the current study, the minimum age of enrolled was 20 years while the maximum age was 90 years. Their mean age was 60.12 years and median was 63.

The age group was ranged between $(<30-\geq$ $80)$ years. The highest age group with positive results with UAT was (60-69) years and the higher incidence of LD is between 50 and 79 years. The distribution of LD according to the age group by urinary antigen test compared with q RT PCR showed in table 4.

\section{Subjects demographic according to gender}

This study enrolled 100 pneumonic patients with atypical pneumonia. Among these; 66
(66\%) were females, and 34(34\%) were males; male to female ratio was $1: 1.9$. The comparison between q RT PCR and UAT according to gender showed in table 5 .

\section{Residence, travel and water associations with LD}

The current study has evaluated the frequency of LD according to the residence. The result showed that, higher frequency of LD in rural 10 $(28.57 \%)$ than in urban 16 (24.62\%). Statically non-significance $(p>0.05)$ association between residence and infection with $L D$.

Both of travel history and bad water system were risk factors for infection. 10/30 (33.33\%) of patients had travel history before 2 weeks 
from onset of the symptoms of LD. Bad water system was highly statistical significance ( $p \leq 0.001$ ) comparable with q RT PCR, which also showed statistical significance $(p=0.012)$, $12 / 31,38.71 \%)$.

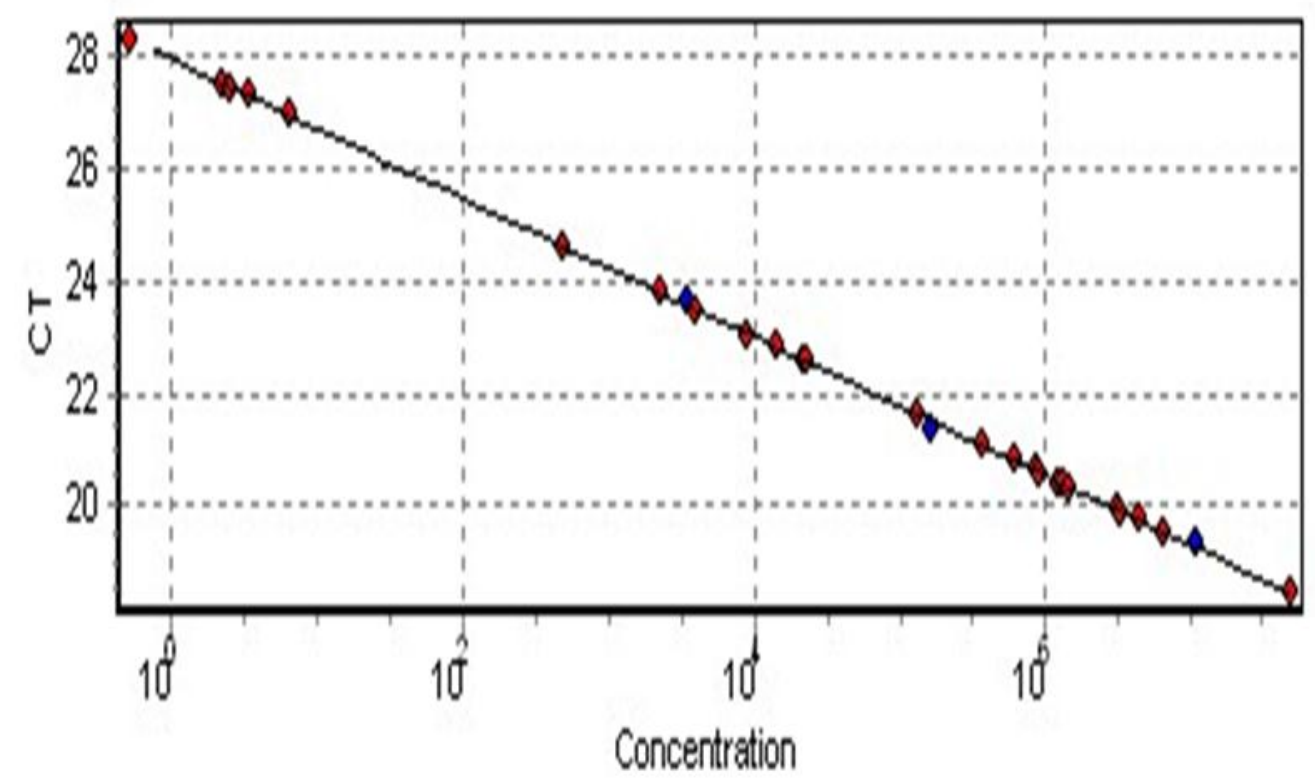

Figure 1. The standard curve of q RT-PCR L. pneumophila mip gene including standards represented by 3 blue squares and 23 positive cases represented by red squares

Table 4. Distribution of LD according to the age group in comparable between UAT and q RT PCR

\begin{tabular}{ccccc}
\hline Age group & $\begin{array}{c}\text { UAT } \\
\text { Positive } \\
\text { No. (\%) }\end{array}$ & $\begin{array}{c}\text { Negative } \\
\text { No. (\%) }\end{array}$ & $\begin{array}{c}\text { Positive } \\
\text { No. (\%) }\end{array}$ & $\begin{array}{c}\text { Negative } \\
\text { No. (\%) }\end{array}$ \\
\hline < 30 years & $1(16.67)$ & $5(83.33)$ & $1(16.67)$ & $5(83.33)$ \\
$\mathbf{3 0 - 3 9}$ years & $3(50.0)$ & $3(50.0)$ & $3(50.0)$ & $3(50.0)$ \\
40-49 years & $2(22.22)$ & $7(77.78)$ & $2(22.22)$ & $7(77.78)$ \\
$\mathbf{5 0 - 5 9}$ years & $6(40.0)$ & $9(60.0)$ & $4(26.67)$ & $11(73.33)$ \\
$\mathbf{6 0 - 6 9}$ years & $7(20.59)$ & $27(79.41)$ & $8(23.53)$ & $26(76.47)$ \\
$\mathbf{7 0 - 7 9}$ years & $6(28.57)$ & $15(71.43)$ & $4(19.05)$ & $17(80.95)$ \\
$\geq \mathbf{8 0}$ years & $1(11.11)$ & $8(88.89)$ & $1(11.11)$ & $8(88.89)$ \\
\hline Total (\%) & 26 & 74 & 23 & 77 \\
\hline P value & \multicolumn{2}{c}{0.507 NS } \\
\hline
\end{tabular}

NS: none statistical significance $(p>0.05)$ 
Table 5. Comparison between UAT and q RT PCR according to the gender

\begin{tabular}{|c|c|c|c|c|c|}
\hline \multirow[b]{2}{*}{ Gender } & \multicolumn{2}{|c|}{$\mathbf{U} \mathbf{A g}$} & \multicolumn{2}{|c|}{ q PCR } & \multirow[b]{2}{*}{ Total (\%) } \\
\hline & $\begin{array}{l}\text { Positive } \\
\text { No. (\%) }\end{array}$ & $\begin{array}{c}\text { Negative } \\
\text { No. (\%) }\end{array}$ & $\begin{array}{l}\text { Positive } \\
\text { No. (\%) }\end{array}$ & $\begin{array}{c}\text { Negative } \\
\text { No. (\%) }\end{array}$ & \\
\hline Male & $7(20.59)$ & $27(79.41)$ & $6(17.65)$ & $28(82.35)$ & $34(34.0)$ \\
\hline Female & $19(28.78)$ & $47(71.21)$ & $17(25.76)$ & $49(74.24)$ & $66(66.0)$ \\
\hline Total (\%) & $26(26)$ & $74(74)$ & $23(23)$ & $77(77)$ & 100(100) \\
\hline$P$ value & \multicolumn{2}{|c|}{$0.376 \mathrm{NS}$} & & $0.361 \mathrm{NS}$ & \\
\hline
\end{tabular}

\section{Residence, travel and water associations with} LD

The current study has evaluated the frequency of $L D$ according to the residence. The result showed that, higher frequency of LD in rural 10 $(28.57 \%)$ than in urban $16(24.62 \%)$. Statically non-significance ( $p>0.05)$ association between residence and infection with LD.

Both of travel history and bad water system were risk factors for infection. 10/30 (33.33\%) of patients had travel history before 2 weeks from onset of the symptoms of LD. Bad water system was highly statistical significance ( $p \leq 0.001$ ) comparable with q RT PCR, which also showed statistical significance $(p=0.012)$, $12 / 31,38.71 \%)$.

\section{Risk factors for legionnaire's disease}

The most important risk factors for LD are diabetes mellitus (DM), smoking, old age, COPD, asthma, renal failure, alcoholism, kidney transplant and malignancy.

According to the risk factors, this study showed that 13 (25.49\%) DM patients, 9 (25\%) smokers, 5 (33.33\%) COPD, 1 (12.5\%) kidney transplant and $1(10 \%)$ as cancer patients. All were developed LD according to UAT and q RT PCR.

\section{Serum electrolyte in LD}

Serum electrolyte especially sodium ( $\mathrm{Na}$ ) may considered as an important laboratory investigation in pneumonic patients suspected LD. Normal range of sodium from (135-145) $\mathrm{mmol} / \mathrm{l}$. In this study, the percentage of hyponatremia were the same as $9 / 28$ (32.14\%) in LD patients by each UAT and q RT PCR testes. Statistically, this study showed non-significant association $(p>0.05)$ between hyponatremia and LD.

\section{Discussion}

In this study, by using UAT and q RT PCR based mip gene, the prevalence of $L D$ in two hospitals in Baghdad were $30 \%$. In Iran the seroprevelance of LD was $17.3 \%{ }^{(8)}$. The spread of this disease in Iraq is due to bad water system. The percentage of sg1 of $L$. pneumophila detected by both UAT and q RT PCR was $82.6 \%$, which is considered true positive and the predominant serogroup responsible for LD in Iraq. Because of those patients have antigen shedding in their urine and gene in their serum is considered to have severe pneumonia. Chen et al. (2015) demonstrated that the percentage of $\mathrm{L}$. pneumophila detected by those tests were $32 \%{ }^{(9)}$. Legionella DNA can be detected in serum within the first two weeks after the onset of symptoms ${ }^{(10)}$. In the other hand, 7 out of $77(9.1 \%)$ patients tested negative in PCR but positive in UAT.

This result may be due to secretion of antigen is early within 2-3 days after infection with Legionella spp. and lasting for months and even for a year as well as the UAG assay may remain positive for up to a year after treatment. While because of low bacterial DNA load in patient's serum or loosing during extraction and storage, PCR assay become negative soon after initiation of therapy ${ }^{(11)}$.

This study reported that four (17.4\%) samples give positive by q RT PCR but negative by UAT, which considered as other serogroups or may be the concentration of antigen in urine is low that Certest determine the detection limit 
value is $6.25 \mathrm{ng} / \mathrm{ml}$. This result agreed with study showed that approximately $8 \%$ of patients with LD do not excrete antigen in their urine ${ }^{(12)}$.

The UAT had higher sensitivity ( $P$ value $<0.001$ ), which means statistically highly significance. Also, the present study showed that UAT highly specific than q RT PCR based mip gene. In France, Maurin et al. (2010) reported that Legionella UAT was positive in $(100 \%)$ of patients and the q RT PCR was displayed a sensitivity $80.4 \%{ }^{(13)}$. Avni et al. (2016) disagree with current results where they noticed that the using of PCR in respiratory samples was much better and higher significance $(p=0.001)$ than that of UAT ${ }^{(14)}$. These differences in result because of differences in sample type, which is include sputum in addition to serum.

In this study, the mean and standard deviation of copy $/ \mathrm{ml}$ of mip gene for L. pneumophila DNA in serum of patients were 8.76 and 16.65 respectively. Bacterial DNA mip gene load were ranged from (0-68.35) copy/ml. This result nearly agreed with mean result but disagree with bacterial DNA load of Maurin et al (2010), they determined the mean were $6.48 \pm 7.29$ and $q$ RT-PCR mip gene ranged from 1.9-8.11 log10 DNA copies/mL which considered high bacterial loads in LRT samples. According to the current result, such patients required prolonged hospitalization in an intensive care unit (13).

The mip gene much higher in serum sample so it is more suitable than sputum for identification of $L$. pneumophila because it has been shown that fewer than half of the Legionnaires' disease patients produce sputum (15) or scanty sputum in atypical pneumonia was release contrasted with large amount of blood obtained from patients. The age group in the current study ranged between (20-90 years) with mean 60.12 and median 63 . Study published in Netherlands in 2008 showed that the mean age of man was 57 years and women were 60 years and the total mean for both were 58.5 while the median age of patients confirmed LD was 54 years ${ }^{(16)}$. This variation with the current study may be due to the differences in number of samples, in addition to different target gene used in RT PCR assay, which is 23S-5S rRNA intragenic spacer region in the comparative study ${ }^{(17)}$.

All age groups were showed positive UAT. The higher incidence of LD is between 30 and 79 years. Touray et al. (2014) reported that there was a higher occurrence among middle-aged participants between 45 and 69 years compared to older and younger participants, which showed low or no infection (18). The current result because of these ages are more associated with environmental, clinical risk factors and most common out door.

This study enrolled 100 pneumonic patients, (66\%) were females, and (34\%) were males. Female infected more than male. The female/male ratio was 1.9:1. A study fulfilled in the European working group on legionella infections criteria of LD demonstrated that (61\%) were males and (39\%) were female and the females / males ratio was 1: $1.4^{(16)}$. While a study achieved in Bulgaria, 2015 showed that female 22/54 more than male $5 / 12$ and the female/male ratio was 4.5:1 ${ }^{(19)}$. This limitation because of most of the male prefers to treat out of the hospital and the differences in the techniques used which is based neither antigen nor gene but antibody IgG, IgM in the comparative studies.

The result showed that, higher frequency of LD in rural (28.57\%) than in urban (24.62\%). This result disagreed with study conducted in Iran showed that LD occurs in city more than in village ${ }^{(8)}$. The explanation of the current result that most of Iraqi rural residence depends on rivers and bad tank water for bathing and house work occupancies.

In this study, $33.33 \%$ of cases were reported as travel-associated whereas $22.86 \%$ were nontravel which is statistically non-significant for LD in Iraq. Four countries (France, Italy, Netherlands and UK) reported that $72 \%$ of all Travel-associated legionnaire's disease (TALD) cases were a risk factor for LD because of tourism ${ }^{(20)}$.

Water system is very important risk factor for infection because $L$. pneumophila is aquatic pathogen. The current study showed highly statistically significant of bad water system as a source for infection. In Iraq, a study conducted on water of Basrah city revealed that the 
percentage of L. pneumophila in water were $71.2 \%{ }^{(21)}$. Other study in Najaf city reported that L. pneumophila isolated from water of dental units, which has been confirmed as an etiological agent for hospital-acquired respiratory tract infection ${ }^{(22)}$. This may be due to variety of health technologies applied in medical and dental practice associated with formation of fine water droplets/aerosols. This presents the potential risk of both the patients and the personnel acquiring Legionnaires' disease ${ }^{(19)}$.

The risk factors for LD include cardiopulmonary disease, cigarette smoking, age $>50$ years, diabetes, malignancy, and immunosuppressive state including glucocorticoid use (17). Accurate existing study detected that DM (25.49\%), smoking (25\%), COPD (33.33\%), kidney transplantation (12.5\%) and cancer (10\%) were non-significant. Predisposing factors for LD asthma (16.67\%) and renal failure (0), were significantly not concedes as a risk factors associated with LD. Cargnelli et al. (2016) disagree with current results, they proved the high prevalence of cigarette smoking (71\%) with LD, then diabetes (29\%), chronic renal insufficiency (29\%), chronic lung disease (14\%), immunosuppression (14\%), which have the same propensity ${ }^{(17)}$.

This study includes (10) patients with hematological and solid organ malignancy. Results revealed that only one patient 1 (10\%) was positive for UAT and q RT PCR mip gene in serum samples, this result disagree with a study done in Iran in 2014, which detected that percentage of mip gene of $L$. pneumophila was (47.5\%) in serum samples, this difference may be due to the differences in sample size ${ }^{(23)}$.

The most common laboratory abnormalities included hyponatremia <134 in LD. In this study, (32.14\%) were hyponatremic patients infected with $L$. pneumophila and detected by UAT and q RT PCR respectively. Statistically, it was no significance ( $p>0.05$ ) because of the result recorded at time of admission. Fiumefreddo et al. (2009) showed hyponatremia in (46\%) was significantly association with LD patients ${ }^{(24)}$. Hyponatremia is a non-specific finding among patients with pneumonia, and it has not been consistently shown to have an association with $\mathrm{L}$. pneumophila when compared to those who had pneumonia due to other causes ${ }^{(25)}$.

This study concluded that high frequency of LD caused by $L$. pneumophila sg1 was observed in Iraqi patients, UAT is a rapid, highly specific and sensitive as a detection tool of LD in pneumonic patients and q RT PCR is a rapid and sensitive tool as a molecular detection of different serogroups of $L$. pneumophila.

Recommendations

This study recommended to prove the other serogroups of these bacteria in Iraqi patients, rapid UAT is reliable for the diagnosis of LD in Iraqi hospitals and serum samples should be used in the diagnosis of LD by q RT PCR.

\section{Acknowledgments}

Authors would like to acknowledge Al-Imamein Al-Kadhimein Medical city and Center of Kidney Diseases and Transplantation in the Medical City of Baghdad for their cooperation in accomplishing this study.

\section{Authors contribution}

Gauad: collection of specimens, DNA extraction, RT PCR and writing of the manuscript. Dr. Abdulrahman: Supervision and performance of DNA extraction and RT PCR run, writing of the manuscript. Dr. Muhamad: Consultant, collection of data and specimen. Jawad: DNA extraction, Gel electrophoresis, DNA purity and concentration measurements. Dr. Hassan: RT PCR interpretation.

\section{Conflict of interest}

Authors declare no conflict of interest.

\section{Funding}

There is no funding source for this research.

\section{References}

1. Moosavian M, Dashti A. Isolation and identification of Legionellosis agents from fishponds, swimming pools and cooling towers in Khuzestan Province, Iran. Jundishapur J. Microbiol. 2017; 2011(4): 209-15.

2. Ricketts KD, Joseph CA on behalf of the European Working Group on Legionella Infection. Legionnaires' disease in Europe 2003-2004. Euro Surveill. 2005; 10(12): 256-9. 
3. Cunha BA, Burillo A, Bouza E. Legionnaires' disease. Lancet. 2016; 387(10016): 376-85. doi: 10.1016/S0140-6736(15)60078-2.

4. Todd B. Legionella pneumonia: many cases of Legionnaire disease go unreported or unrecognized. Am J Nurs. 2005; 105(11): 35-6, 38.

5. Center for Disease Control and Prevention. 2013. Legionella (Legionnaires Disease and Pontiac fever). http://www.cdc.gov/legionella/clinicians.html (accessed 6/29/2015).

6. Benson RF, Tang PW, Fields BS. Evaluation of the Binax and Biotest urinary antigen kits for detection of Legionnaires' disease due to multiple serogroups and species of Legionella. J clin Microbiol. 2000; 38(7): 2763-5.

7. Hayden R T, Uhl J R, Qian X, et al. Direct detection of Legionella species from bronchoalveolar lavage and open lung biopsy specimens: comparison of LightCycler PCR, in situ hybridization, direct fluorescence antigen detection, and culture. J Clin Microbiol. 2001; 39(7): 2618-26. doi: 10.1128/JCM.39.7.2618-2626.2001.

8. Alavi SM, Moshiri N, Mmoosavian $M$, et al. Seroprevalence of Legionella pneumophila in admitted patients with pneumonia in training hospitals, Ahvaz, Iran (2007-2008). Pak J Med Sci. 2009; 25(5): 811-6.

9. Chen DJ, Procop GW, Vogel S, et al. Utility of PCR, culture, and antigen detection methods for diagnosis of legionellosis. J Clin Microbiol. 2015; 53(11): 34747. doi: 10.1128/JCM.01808-15.

10. Matsiota-Bernard P, Waser S, Vrioni G. Detection of Legionella pneumophila DNA in urine and serumsamples from patients with pneumonia. Clin Microbiol Infect. 2000; 6(4): 223-5.

11. Korosec $P$, Silar $M$, Erzen R, et al. The influence of antimicrobial therapy on the sensitivity of Legionella PCR. Scand J Infect Dis. 2006; 38(10): 925-8. doi: 10.1080/00365540600561777.

12. Muñoz MJ, Martínez Toldos MC, Yagüe G, et al. Evaluation of three immunochomatographic assays for detection of Legionella pneumophila serogroup 1 antigen in urine sample. de la Sociedad Espanola de Quimioterapia. 2009; 22(4):207-9.

13. Maurin M, Hammer L, Gestin B, et al. Quantitative real-time PCR tests for diagnostic and prognostic purposes in cases of legionellosis. Clin Microbiol Infect. 2010; 16(4): 379-84. doi: 10.1111/j.14690691.2009.02812.x.

14. Avni $T$, Bieber A, Green $H$, et al. Diagnostic accuracy of PCR alone and compared to urinary antigen testing for detection of Legionella spp.: a systematic review. J Clin Microbiol. 2016; 54(2): 401-11. doi: 10.1128/JCM.02675-15.

15. Murdoch DR. Diagnosis of Legionella infection. Clin Infect Dis. 2003; 36(1): 64-9. doi: 10.1086/345529.
16. Diederen BMW, Kluytmans Jan AJW, VandenbrouckeGrauls CM, et al. Utility of Real-Time PCR for Diagnosis of Legionnaires' Disease in Routine Clinical Practice. J. clin. Microbial. 2008; 46(2): 671-7. doi: 10.1128/JCM.01196-07.

17. Cargnelli S, Powis J, Tsang JLY. Legionella pneumonia in the Niagara Region, Ontario, Canada: a case series. J Med Case Rep. 2016; 10(1): 336. doi: 10.1186/s13256-016-1105-2.

18. Touray S, Newstein MC, Lui JK, et al. Legionella pneumophila cases in a community hospital: A 12month retrospective review. Original Article: SAGE Open Med. 2014; 2: 2050312114554673. doi: $10.1177 / 2050312114554673$.

19. Kevorkyana A, Tomovab I, Raychevac R, et al. Legionella pneumophila antibodies in serum samples from medical and dental personnel: a seroepidemiological survey. Biotechnol Biotechnol Equip. 2017; 31(3): 588-93. doi: http://dx.doi.org/10.1080/13102818.2017.1290549.

20. European Centre for Disease Prevention and Control ECDC. Legionnaires' disease in Europe, surveillance report. 2011. p. 1-41. doi 10.2900/78974.

21. Al-Sulami AA, Al-Taee AMR, Yehyazarian AA. Isolation and identification of Legionella pneumophila from drinking water in Basra governorate, Iraq. East Mediterr Health J. 2013; 19(11): 936-41.

22. Alsehlawi ZS, Al-Yasiri I K, Fakhriddeen A J, et al. Antibiotic Susceptibility Patterns of Legionella Pneumophila Isolated from Water Lines of Dental Settings. Smile Dent J. 2016; 11(4): 36-9. doi: 10.12816/0034781.

23. Farzi N, Abrehdari-Tafreshi Z, Zarei O, et al. Detection of Legionella Pneumophila in urine and serum specimens of neutropenic febrile patients with haematological malignancies. Int J Hematol Oncol Stem Cell Res. 2017; 11(1): 49-53.

24. Fiumefreddo R, Zaborsky R, Haeuptle J, et al. Clinical predictors for Legionella in patients presenting with community-acquired pneumonia to the emergency department. BMC Pulm Med. 2009; 9: 4. doi: 10.1186/1471-2466-9-4.

25. Cunha BA. Severe Legionella pneumonia: rapid presumptive clinical diagnosis with WinthropUniversity Hospital's weighted point score system (modified). Heart Lung. 2008; 37(4): 311-20. doi: 10.1016/j.hrtlng.2007.12.003.

\section{Correspondence to Dr Thanaa R. Abdulrahman E-mail: thanaraaa1970@yahoo.com Thanaa.rasheed@colmed-alnahrain.edu.iq Received Nov. $2^{\text {nd }} 2017$ Accepted Jan. 21 2018}

